\title{
Maternal mortality: A hospital based study in thirty nine years"
}

\author{
K Pratima Devi ${ }^{1}$, L Ranjit Singh $^{2}$, M Rameshwar Singh ${ }^{3}$, \\ $\mathrm{Ng}$ Nabakishore Singh ${ }^{4}$, ChManglem Singh ${ }^{5}$ \\ ${ }^{1}$.Registrar, ${ }^{2}$.Professor, ${ }^{3}$ Associate Professsor, ${ }^{4}$. Professor \& Head, ${ }^{5}$. Professor \\ Department of Obstetrics \& Gynecology, Regional Institute of Medical Sciences(RIMS),Imphal, India
}

\section{Introduction}

Maternal and child health is the cornerstone of the health of a nation. Death of the mother is a neglected tragedy for the child, family and the society. Persistent high levels of maternal mortality not only reflects poor quality of maternity services facilities prevalent but in reality it is an index of the socio-economic status or poverty, ignorance, inadequate medical facilities and social customs of the people. In the last decade, augmentation of health care facilities for mothers and children has facilitated reduction of maternal and per-natal mortality appreciably. Maternal deaths account for less than 2 percent of all deaths in women of reproductive age in developed countries compared to 10-15 percent in developing countries. Up to 80 percent of these deaths are directly due to five major complications: hemorrhage, sepsis, pregnancy induced hypertension, rupture uterus (obstructed labor) and complications of illegal abortion. A major reason why many patients die from hemorrhage is because once bleeding starts death can occur in around 2 hours compared to 10 hours for eclampsia and 72 hours for obstructed labor[1]. India alone accounts for over 20 percent of the global maternal deaths even though it has only 16 percent of world population. Every minute a woman dies as a result of pregnancy and childbirth related complications somewhere in the world of which $99 \%$ are in the developing countries that includes India. When one mother dies, other sixteen mothers suffer from severe morbidities. Some of the disabilities may be permanent. According to WHO (2005) 536,000 women die globally each year from complications of pregnancy and childbirth estimating a global maternal mortality ratio (MMR) of 400. The MMR is estimated to be 920 in Africa, 330 in Asia and 10 in Europe [2].The United Nations issued 8 Millennium Development Goals (MDG); the fifth goal (MDG-5) stipulated a reduction of the maternal mortality rate by 75 percent by 2015[3].In India National Rural Health Mission sets a target of MMR of 100/1lakh by 2012. The level of MMR in India has declined from over 750 in the sixties to about 400 in the nineties [4, 5].It has further declined from 254 in 2004-06 to 212 in 2007-2009[6] as published in the recent bulletin.

\section{Aims and Objectives}

The study was aimed at evaluating the spectrum of causes of maternal deaths at a tertiary care centreof India in the far north east, to find out the avoidable factors and to identify measures for further reduction at par with developed countries.

\section{Materials And Methods}

The present study was based on a primary data of 238225 live births occurred during January 1972 to December, 2010 at Regional Institute of Medical Sciences hospital, Imphal, Manipur, India. The data was analyzed through SPSS package using $\mathrm{x}^{2}$ test and $\mathrm{p}$ value of $<0.05$ was taken as significant.

\section{Results}

During the study period, there were 353 maternal deaths out of 2,38,225 live births giving MMR of 148.12 per 100000 live births (Table 1). The MMR was 191.50 in 1972 but today it has come down to 114.42. The most common cause of maternal deaths was hemorrhage (Table 1) and lowest MMR was seen in the 21-30 years age group (121.8) as shown in Table 2 . A very significant test value $p<0.001$ ascertains that age of the mothers play a very important role in maternal death. There is a positive correlation between parity and MMR except in P1 where MMR was lowest (69.9) but increases with higher parity which was statistically significant (Table 3). There is a sharp variation in MMR between literate mothers (22.4) and illiterate ones (321.6) as shown in Table 4. Further, $\mathrm{p}<0.001$ highlights that the difference of rates is significant in the sense that education of the mothers have a link with maternal death through other prognostic factors like health awareness, immunization, routine antenatal checkup, etc. 


\section{Discussion}

The MMR in the study was 148.1 per 100,000 live births and varied from 191.5 in 1972 to 114.4 in 2010. Most of the women were from far remote places resulting in delayed transportation from the place of birth and many were in poor general condition at the time of admission. Other studies from tertiary care institutions reported mortality rate of 371 to 4286 per 100,000 live births due to large number of referred cases [7].We might have underestimated the levels of maternal mortality either because death reporting was incomplete or because pregnancy was underreported as a cause of death. The higher incidence of deaths is due to late referral of cases from periphery and delayed intervention. Most deaths were observed in the 21-30 years age group as reported in other studies [8]. MMR was highest in the age group above 40 years (290.7) while lowest in the age group of 21 to 30 years $(121.8)$ as in Table 2 . A very high significant value $(\mathrm{P}<0.001)$ ascertains that age of the mothers has a very important role in maternal death. There is a positive correlation between parity and MMR. As parity advances MMR increases except in para1 where there was lowest MMR (69.9). High MMR was seen among illiterate mothers and unbooked cases. Majority (52\%) of deaths occurred within the first 24 hours of admission to the hospital. Postpartum deaths accounted for about 55 percent. These are mainly due to domiciliary delivery attended by traditional birth attendants brought late because of late referral and delayed transport.

Hemorrhage $(46.18 \%)$ and sepsis $(20.40 \%)$ were the major direct killers and were comparable to other studies [9].The availability of blood transfusion facility at all first referral units (FRUs) can save many lives. A recent systemic review of the causes of deaths stressed the need for increased emphasis on prevention and treatment of obstetric hemorrhage and noted that most post-partum deaths should be avoidable by appropriate management [10].Sepsis included both puerperal sepsis due to home delivery and illegal abortions carried out by unskilled personnel under unhygienic conditions. Many of these lives could be saved if all abortions and deliveries were performed by trained medical personnel at appropriate health care facilities. There is lack of awareness about contraceptive practice to avoid unwanted and unintended pregnancies. Practice and knowledge of basic aseptic techniques is essential at all levels[11].

Hypertension or eclampsia related deaths accounted for 10.48 percent which was comparable with other studies[8,12].Use of magnesium sulfate and early termination of pregnancy with medications have led to better outcome in cases of severe pre-eclampsia and eclampsia. Amniotic fluid and pulmonary embolism were responsible for $2.83 \%$ and $1.13 \%$ each. Inversion of uterus accounted for $2.55 \%$ and this was similar wit the study by JadhavAsha and Rote Priyanvada[13].

Indirect causes of maternal deaths was observed in $16.43 \%$ and of which anemia constituted $4.81 \%$. Routine supplementation of iron and folic acid is of proven value. Pre-existing anemia worsens as pregnancy advances leading to heart failure and maternal death. It also impairs mothers' ability to resist infection or cope with hemorrhage and there is increased chance of her dying in childbirth by a factor of four [7].Hepatitis accounted $2.27 \%$ deaths though other studies reported 4.16 to 10.8 percent deaths [7,8].There is lack of freely available routine screening of viral hepatitis profile and proper monitoring of the disease process. Other indirect causes like cardiac disease, malaria, epilepsy, asthma etc. played a minor role in contributing maternal deaths.

\section{Figures and Tables}

Table 1: Different causes of maternal deaths

\begin{tabular}{|c|c|c|c|}
\hline Sl no & Causes of maternal deaths & No. of deaths & Percentage \\
\hline \multirow[t]{14}{*}{1} & Direct & 295 & 83.57 \\
\hline & Hemorrhage & 163 & 46.18 \\
\hline & Atony & 56 & \\
\hline & Antepartum haemorrhage & 39 & \\
\hline & Adherent placenta & 19 & \\
\hline & Rupture uterus & 19 & \\
\hline & Ectopic rupture & 10 & \\
\hline & Disseminated intravascular coagulation (DIC) & 10 & \\
\hline & Molar pregnancy & 10 & \\
\hline & Infection (Sepsis) & 72 & 20.40 \\
\hline & Preeclampsia and eclampsia & 37 & 10.48 \\
\hline & Amniotic fluid embolism & 10 & 2.83 \\
\hline & Acute inversion of uterus & 9 & 2.55 \\
\hline & Pulmonary embolism & 4 & 1.13 \\
\hline \multirow[t]{12}{*}{2} & Indirect & 58 & 16.43 \\
\hline & Anemia & 17 & 4.81 \\
\hline & Infective Hepatitis & 8 & 2.27 \\
\hline & Cerebral Malaria & 8 & 2.27 \\
\hline & Cerebrovascular Accident (CVA) & 7 & 1.99 \\
\hline & Cardiac Arrest & 6 & 1.70 \\
\hline & Encephalitis & 6 & 1.70 \\
\hline & Human immunodeficiency Virus (HIV)/AIDS & 2 & 0.57 \\
\hline & Terminal stage of cancer breast & 1 & 0.28 \\
\hline & Renal failure & 1 & 0.28 \\
\hline & Status asthmaticus & 1 & 0.28 \\
\hline & Status epilepticus & 1 & 0.28 \\
\hline Total & Number of maternal deaths & 353 & 100 \\
\hline
\end{tabular}


Table 2: Age distribution

\begin{tabular}{|l|l|c|l|l|l|l|}
\hline Age (years) & Livebirths & Maternal deaths & MMR & $X^{2}$ & df & P value \\
\hline $16-20$ & 21679 & 48 & 221.4 & & & \\
\hline $21-30$ & 145318 & 177 & 121.8 & & & \\
\hline $31-40$ & 68133 & 119 & 174.6 & & & \\
\hline $41 \&$ above & 3095 & 9 & 290.7 & & & \\
\hline Total $(\mathrm{n})$ & 238225 & 353 & 148.1 & 1003.788 & 5 & $<0.001$ \\
\hline
\end{tabular}

Table 3: Parity-wise distribution of MMR

\begin{tabular}{|l|l|l|l|l|l|l|}
\hline Parity & Live births & Maternal deaths & MMR & $X^{2}$ & df & P value \\
\hline P0 & 100054 & 91 & 90.09 & & & \\
\hline P1 & 71468 & 50 & 69.9 & & & \\
\hline P2 & 47622 & 56 & 117.5 & & & \\
\hline P3 & 10680 & 43 & 402.6 & & & \\
\hline P4 & 4504 & 44 & 976.9 & & & \\
\hline P5+ & 3897 & 69 & 1770.5 & & & \\
\hline Total & 238225 & 353 & 188.1 & 1003.788 & 5 & $<0.001$ \\
\hline
\end{tabular}

Table 4: Literacy wise distribution of MMR

\begin{tabular}{|l|l|l|l|l|l|l|}
\hline Literacy & Live births & Maternaldeaths & MMR & X2 & df & P value \\
\hline Literate & $1,38,123$ & 31 & 22.4 & & & \\
\cline { 1 - 4 } & & & 321.6 & & & \\
\cline { 1 - 5 } Tlliterate & $1,00,102$ & 322 & 148.1 & 351.223 & 1 & $<0.001$ \\
\hline
\end{tabular}

Table 5: Inhabitant wise distribution

\begin{tabular}{|l|l|l|l|l|l|l|}
\hline Inhabitant & Live births & Maternal deaths & MMR & X2 & df & P value \\
\hline Rural & 145041 & 276 & 189.9 & & & \\
\cline { 1 - 3 } Urban & 92831 & 77 & 82.8 & \multirow{2}{*}{43.896} & \multirow{2}{*}{1} & $<0.001$ \\
\cline { 1 - 4 } Total & 238225 & 353 & 148.1 & & & \\
\hline
\end{tabular}

Table 6: Type of treatment-wise distribution

\begin{tabular}{|l|l|l|l|l|l|l|}
\hline Type of treatment & Live births & Maternal deaths & MMR & X2 & df & P value \\
\hline Booked & $1,40,553$ & 47 & 33.4 & & & \\
\cline { 1 - 3 } & 97,672 & 306 & 313.2 & & & \\
\cline { 1 - 4 } Total & $2,38,225$ & 353 & 148.1 & 305.030 & 1 & $<0.001$ \\
\hline
\end{tabular}

It is observed that women residing at urban area, booked cases have lower MMR than their rural counterpart and un-booked cases (Table 5 and 6). Fifty two percent of the deaths occurred during the first 24 hours (Fig 1). Fifty five percent of deaths occurred in the postpartum period (Fig 2).

Fig 1: Pie diagram showing distribution of time interval of deaths to admission

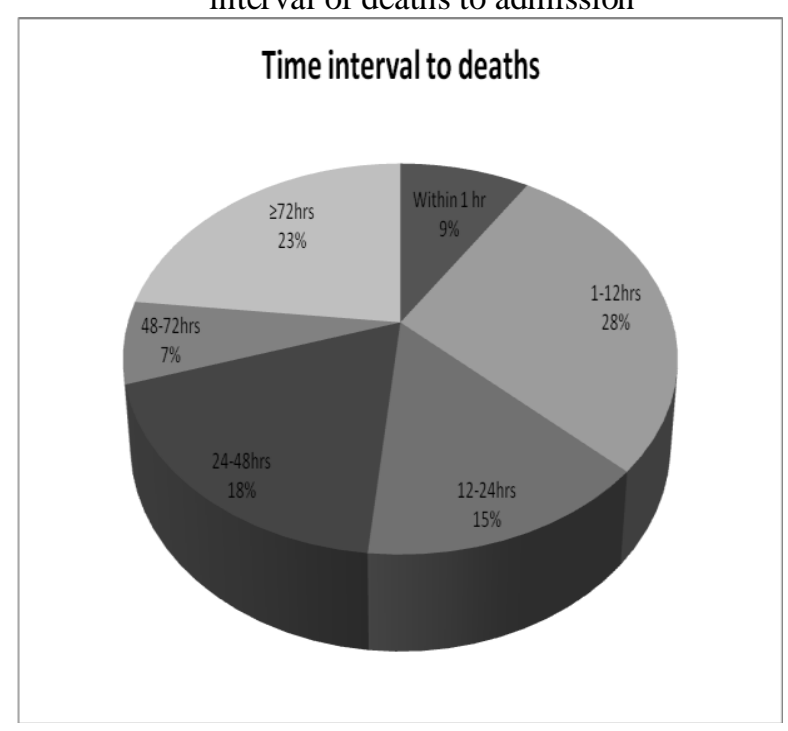

Fig 2: Showing distribution of deaths in relation to obstetric events

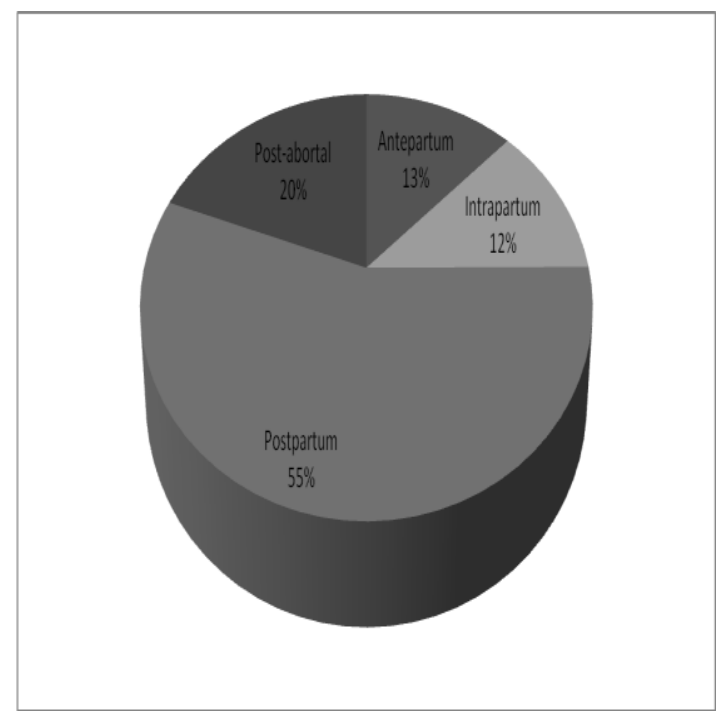




\section{Conclusion}

Maternal death is most common in the age group of 21 to 30 years and it also increases with increasing parity. Maternal mortality is also high among illiterate, un-booked women from rural areas. Bad roads and inhospitable hilly terrains make it difficult for patients to reach referral hospital in time. Much needs to be done for maternal health care in rural areas, as most of the deaths reported are referred from peripheral health centers in moribund state. Maternal mortality and morbidity are related to high levels of fertility. We need to increase female literacy and access to effective contraceptive. Regular maternal audit is necessary to give guidelines for emergency obstetric care. Saving mothers require early detection of the obstetric complications at home, at the health care centre, timely referal of complications, emergencies at the appropriate level of health care and effective interventions without delay, using appropriate skills and equipments. Interventions in maternal and child health are the most cost effective ones. This is not only for women of today but also for mother and children of tomorrow.

\section{References}

[1]. Rao KA. Presidential address.The $44^{\text {th }}$ All India Obstetric and Gynecological congress.Ahmedabad. December 27, 2000. J ObstetGynecol India 2001; 51: 25-8.

[2]. WHO/UNICEF/UNFPA. Maternal mortality in 2005. Estimates Developed by WHO, UNICEF, UNFPA and the world Bank. Geneva: WHO, 2007.

[3]. AICOG Committee Opinion. Number 283, May2003.New US.Food and drug administration labeling on cy tolog (misoprostol) use and pregnancy.ObstetGynecol 2003; 101: 1049-50.

[4]. United Nations. UN Millennium Development Goals web site. http: // www.un.org/ millennium goals/.Accessed $1^{\text {st }}$ August 2009

[5]. Bhat P N, Navneetham K, Rajan SI. Maternal mortality in India: Estimates from a regression model. Stud FamPlann 1995; 26: 21732.

[6]. Registrar General. Special Bulletin on Maternal mortality in India 2007-09.Sample registration system. New Delhi, Government of India, 2011.

[7]. Bedi N, Kambo I, Dhillon BS etal. Maternal deaths in India: preventable tragedies.(An ICMR Task Force Study). J ObstetGynecol India 2001; 51: 86-92.

[8]. Verma Ashok, MinhnasSantosh, Santosh, SoodAnupa.A study on maternal mortality. J ObstetGynecol 2008; 58:226-9.

[9]. Bates I,Chapotera G, McKew S, van den Broek N. Maternal mortality in sub-Sahara Africa: the contribution of ineffective blood transfusion services. BJOG 2008;115:1331-9

[10]. Khan KS, Wojdyla D, SayL, Gulmezoglu AM, Van Look PL. WHO analysis of causes of maternal death: a systematic review. Lancet 2006; 367: 1066-74.

[11]. Pathak Dinesh, ChakrabortyBarunoday, GoswamiSebanti, AdhikariSudhir. Changing Trends of Maternal Mortality: A comparative study. J ObstetGynecol India 2011; 61: 161-5.

[12]. AbhaAggarwal, ArvindPandey, B N Bhattacharya. Risk factors for maternal mortality in Delhi slums: A community-based case control study. Indian J Med Sci 2007;61: 517-26

[13]. JadhavAshaJagdish, Rote PriyanvadaGovind. Maternal mortality- changing trends. J ObstetGynecol 2007; 57: 398-400. 